\title{
GESTÃO DE MARCAS VERDES NO SETOR HOTELEIRO
}

\author{
Paula Felipe Schlemper, Dra. (IFB); Jackeline do Socorro Benas- \\ suly Barbosa, MSc. (IFB); Marcely Ferrreira Nascimento, MSc.
}

(IFB)

\author{
PALAVRAS-CHAVE \\ Gestão de marcas, marcas verdes, sustentabilidade
}

\section{RESUMO}

A incompatibilidade entre desenvolvimento sustentável e os padrões de produção e consumo, sugere que as organizações incorporem práticas de gestão sustentável nos seus negócios, de forma a conciliar o crescimento econômico com as questões ambientais e sociais. As exigências de diferentes perfis de clientes a todo o momento, força o setor hoteleiro a se transformar para implementar no cerne das operações hoteleiras, os três principais pilares da sustentabilidade: o econômico, o social e o ambiental, visando a redução de riscos, redução de custos, aumento das receitas e fortalecimento da marca. O presente artigo tem como proposta ampliar os conhecimentos acerca da gestão de marcas verdes no setor hoteleiro. $O$ estudo aborda aspectos teóricos sobretudo acerca do turismo sustentável e da gestão de marcas verdes, além de um estudo de campo da gestão de marcas verdes no setor hoteleiro de Brasília.

\section{INTRODUÇÃO}

A marca atualmente pode ser compreendida como uma imagem visual coesa e consistente que pode ser usada para dar a empresa um estilo, uma imagem e uma personalidade. Nesse sentido, pode-se definir a gestão de marcas (branding) como o processo de luta contínua entre empresas e consumidores para definir a promessa e o significado das marcas (HEALEY, 2008), e a gestão de marcas verdes (green branding), por sua vez, pode ser compreendida como o processo de gestão de marcas que "ligando o tecnicamente possível com o ecologicamente necessário, faz nascer novas propostas que sejam social e culturalmente apreciáveis" (MANZI$\mathrm{Nl}$; VEZZOLI, 2002, p. 20).

Devido a elevada semelhança das características técnicas do produto, o branding encontra-se em crescente ascensão por contribuir nesse processo de diferenciação da concorrência e criação do valor de marca (Bürdek, 2006). Dessa forma, além das vendas e do market share, as empresas tem trabalhado para obter valor de marca, zelando pelos valores funcionais e emocionais, que prometem uma experiência única da marca. Este é um processo contínuo, que exige constante preocupação acerca de todos 
os fatores de promoção de experiências para os consumidores que corroboram para a percepção de uma imagem de marca forte e duradoura, afinal "a marca é qualquer ponto de contato e qualquer ideia que um cliente forma sobre ela" (Calkins, 2006, p. 6).

Paralelamente a essa valorização das marcas no mundo corporativo, observa-se também uma crescente e acelerada preocupação acerca dos modelos de desenvolvimento. A Agenda 21 (Conferência das Nações Unidas sobre meio ambiente e desenvolvimento) instituída durante a ECO-92 no Rio de Janeiro, o Protocolo de Kyoto (1997), o Tratado de Joanesburgo (2002), a criação de certificações ecológicas como a ISO 14001, e posteriormente a ISO 26000 , demonstram que a sociedade está atenta aos déficits dos modelos de gestão vigente e clamam por novos modelos de desenvolvimento econômico que conciliem o desenvolvimento social e ambiental.

Considerando que as políticas de desenvolvimento sustentáveis se referem ao interdependente e mútuo reforço da relação entre o desenvolvimento econômico, o desenvolvimento social e a proteção ambiental, o presente artigo visa contribuir para ampliar os conhecimentos acerca da gestão de marcas verdes no setor hoteleiro.

Para tanto, apresenta uma revisão bibliográfica de alguns conceitos norteadores do estudo, os procedimentos metodológicos utilizados e os resultados e análises obtidos na pesquisa de campo, realizada no setor hoteleiro de Brasília. Como parâmetros para o desenvolvimento do questionário que foi aplicado junto aos gerentes dos hotéis pesquisados, procurou-se utilizar indicadores ligados a diferentes dimensões de sustentabilidade, assim como indicadores da área de gestão de marcas, selecionados e adaptados para os objetivos do estudo.

\section{DESENVOLVIMENTO SUSTENTÁVEL}

Na segunda metade do século passado, os países, na busca do desenvolvimento econômico desenfreado, provocaram inúmeros problemas socioambientais em escala global. Essa bus- ca constante pelo desenvolvimento a qualquer custo, aliada à ideia de que os recursos naturais eram infinitos, promoveu o uso inadequado desses recursos, degradando a qualidade ambiental e comprometendo de forma significativa a sua preservação. Diante desse cenário de graves problemas socioambientais, surgiu uma intensa mobilização para encontrar um novo modelo de desenvolvimento que permitisse compatibilizar aspectos econômicos, sociais e ambientais (VIEGAS, 2008).

Neste contexto surgia no início da década de 70 do século XX o novo modelo de desenvolvimento econômico, conhecido como desenvolvimento sustentável, passando a incorporar o conceito da humanização de desenvolvimento, incluindo a preocupação com a preservação dos recursos naturais para as futuras gerações. Assim, em 1983, as Nações Unidas incumbiram uma comissão especial para desenvolver um plano a longo termo de desenvolvimento sustentável e em 1987 um relatório foi publicado.

Segundo este relatório, o desenvolvimento sustentável é o desenvolvimento que satisfaz as necessidades do presente sem comprometer a capacidade das gerações futuras de satisfazer as suas próprias necessidades (BRUNDTLAND, 1987). Embora existam várias definições para o desenvolvimento sustentável (ou sustentabilidade), esta é a mais usada. As três áreas da sustentabilidade estão concentradas na sociedade, na economia e no meio ambiente. Juntas, elas são conhecidas como Triple Bottom Line (TBL) ou tripé da sustentabilidade (DAHLSTROM, 2011).

A preocupação com as práticas sustentáveis teve como marco a Conferência das Nações Unidas sobre o Ambiente Humano, em Estocolmo - 1972, na Suécia. Este evento reuniu centenas de líderes mundiais e teve como resultados a elaboração de uma declaração e um plano de ação mundial para orientar a preservação e meIhoria no ambiente humano. A Conferência Internacional de Meio Ambiente e Desenvolvimento, em 1992, no Rio de Janeiro - Brasil foi outro marco importante da questão ambiental. Seu foco foi criar uma agenda de cooperação internacional para preservação ambiental, cujas práticas fossem desenvolvidas ao longo do século XXI. 
Diante dessa perspectiva, sendo o setor turístico, particularmente o segmento hoteleiro, um importante fator de desenvolvimento econômico, este novo paradigma logo é incorporado às práticas socioambientais dos meios de hospedagem contribuindo para o desenvolvimento sustentável. De acordo com Turczynski e Oliveira (2011), a adoção de práticas sustentáveis no setor hoteleiro, no entanto, tem como objetivo também a obtenção de benefícios monetários, crescimento e competitividade. Estudos recentes constatam que a mudança de postura dos empreendimentos, em relação ao meio ambiente, tende a acontecer por pressões derivadas da mudança de comportamento dos hóspedes (CADERNO VIRTUAL DE TURISMO, 2010).

\subsection{TURISMO SUSTENTÁVEL}

Segundo Barros (2013), o setor de turismo ocupa atualmente relevante papel na economia mundial, sendo uma das atividades com maior representatividade econômica, ao lado da indústria do petróleo.

A sustentabilidade do turismo é baseada em um conjunto mínimo de princípios estabelecidos pelo Conselho Brasileiro para o Turismo Sustentável (CBTS), referência nacional para o Turismo Sustentável. São eles: respeitar a legislação vigente; garantir os direitos das populações locais; conservar o ambiente natural e sua biodiversidade; considerar o patrimônio cultural e os valores locais; estimular o desenvolvimento so-

Quadro 1 - Requisitos Ambientais, socioculturais e econômicos

REQUISITOS AMBIENTAIS - RA

1. $\mathrm{RA}_{1}$. Preparação e atendimento a emergências ambientais.

2. $\mathrm{RA}_{2}$ Incentivo à preservação e à recuperação de áreas naturais (um dos principais atrativos turísticos).

3. $\mathrm{RA}_{3}$ Arquitetura do empreendimento integrada à paisagem, minimizando os impactos da implantação, durante a construção, a operação e, quando houver obras.

4. $\mathrm{RA}_{4}$. O planejamento e operação do paisagismo deve refletir o ambiental natural do entorno, com o uso de espécies nativas, desde que não sejam provenientes de extração ilegal.

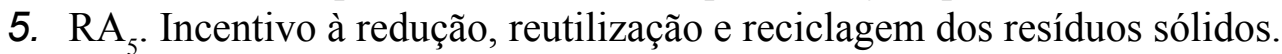

6. RA. Incentivo à coleta e posterior tratamento de efluentes líquidos.

7. $\mathrm{RA}_{7}$. Incentivo à coleta e posterior tratamento de emissões gasosas. $\mathrm{O}$ empreendimento deve adotar medidas de minimização de emissão de gases e odores provenientes de veículos, instalações e equipamentos.

8. $\mathrm{RA}_{8}$. Redução do consumo de energia, em particular de fontes não renováveis.

9. $\mathrm{RA}_{9}$. Conservação e gestão do uso de água.

10. $\mathrm{RA}_{10}$. Promoção do uso de insumos biodegradáveis.

\section{REQUISITOS SOCIOCULTURAIS - RS}

$\mathrm{RS}_{1}$. Contribuir para o desenvolvimento das comunidades locais.

$\mathrm{RS}_{2}$. Geração de trabalho e renda para a comunidade local.

$\mathrm{RS}_{3}$. Promoção da equidade étnica, social e de gênero, principalmente no ambiente de trabalho.

$\mathrm{RS}_{4}$. Divulgação da cultura local entre os seus clientes.

$\mathrm{RS}_{5}$. Preservação das tradições e de sua autenticidade.

\section{REQUISITOS ECONÔMICOS - RE}

$\mathrm{RE}_{1}$. Avaliar a viabilidade econômica do empreendimento.

$\mathrm{RE}_{2}$. Planejar produtos e serviços considerando as expectativas dos clientes.

$\mathrm{RE}_{3}$. Promoção da saúde e segurança dos clientes e funcionários do empreendimento. 
cial e econômico dos destinos turísticos; garantir a qualidade dos produtos, processos e atitudes e estabelecer o planejamento e a gestão responsáveis (SÃO PAULO, 2005).

Além dos princípios para o turismo sustentável, cabe ressaltar os requisitos da atividade turística, analisados a partir de três grandes dimensões: ambiental, sociocultural e econômica (Quadro 1).

De forma a concretizar a implementação desses requisitos (ambiental, sociocultural e econômico), em 1996, surge a série de normas ISO 14000, estabelecendo especificações para os sistemas de gestão ambiental, aplicáveis a todos os tipos de organizações e amplamente utilizadas (BARROS, 2013). A norma ISO 14001 foi elaborada com o intuito de conscientizar as empresas no tocante aos efeitos que elas provocam ao meio ambiente e a ISO 26000 fornece orientações para as organizações sobre conceitos, termos, definições e todas as questões referentes à responsabilidade social e desenvolvimento sustentável.

Segundo Alberton e Costa Jr (2007), as principais razões para que as empresam busquem a certificação estão relacionadas à necessidade de demonstrar um desempenho ambiental capaz de atender os padrões ambientais vigentes, de prevenir impactos ao meio ambiente, de fortalecer a imagem institucional junto à comunidade, reduzir o risco de multas e penalidades e consequentemente aumentar a competitividade.

Considerando que o setor de hotelaria, junto com transportes, restaurantes (alimentos e bebidas), planejamento de eventos, parques temáticos e cruzeiros marítimos, constituem o setor de turismo (BARROS, 2013), salienta-se que os empreendimentos hoteleiros devem estabelecer e manter um sistema de gestão da sustentabilidade de modo a assegurar o atendimento continuado e sistemático dos princípios do turismo sustentável.

\section{GESTÃO DE MARCAS}

Parece óbvio definir a palavra marca, uma vez que se conhece e convive diariamente com muitas delas. Mas se perguntarmos para algumas pessoas, dependendo de sua atividade, como por exemplo, para um fabricante, para um jurista, para um designer, entre outros, provavelmente, observa-se diferenças nas respostas obtidas. A razão pelo qual isso acontece pode ser considerada simples. A marca, atualmente, pode ser compreendida, por exemplo, como um fenômeno socioeconômico, político, cultural, legal e formal.

Perez (2004) afirma que a marca, como conceito mercadológico, refere-se a um termo, sinal, ou a combinação destes, tendo por objetivo distinguir uma oferta de outras. A marca, portanto, funciona como um tipo de bandeira, acenando aos consumidores, provocando a consciência ou lembrança do produto e diferenciando-o da concorrência (ELWOOD, 2004).

Mozota (2011, pp. 125-126) vai além ao ressaltar que uma marca é mais do que "um nome, termo, signo, símbolo ou design, ou combinação destes, para identificar os produtos e serviços de um vendedor ou grupo de vendedores e diferenciá-los da concorrência". Uma marca é a soma de todas as características - tangíveis e intangíveis - que tornam única a oferta. Ela representa um conjunto de percepções que são direcionadas por comunicações e experiências, produzindo valor agregado. A marca representa, dessa forma, a percepção do consumidor e sua interpretação de um agrupamento de atributos, benefícios e valores associados a ela (BATEY, 2010). O autor ressalta, portanto, que as percepções da marca só existirão, do ponto de vista do significado, à medida que os consumidores passarem a conhecê-la e a ganhar experiências com o produto - a partir da compra, do uso, da experimentação.

Apesar de serem influenciados pela propaganda e publicidade do fabricante, vendedor, ambiente ou evento, os consumidores formam seus próprios sentimentos acerca do que as marcas significam. A gestão de marcas - branding é justamente esse processo de luta contínua entre produtores e consumidores para definir essa promessa e significado (HEALEY, 2008). 
Tavares (2008) ressalta que o branding se propõe a fortalecer e valorizar a marca como um diferencial competitivo da empresa. Esse fortalecimento deve ser construído por meio de um relacionamento emocional dos clientes com a marca, de forma que ela exerça um apelo emocional sobre os consumidores, permitindo que se torne importante pelo que simboliza e não apenas nas considerações racionais e utilitárias que o consumidor possa ter.

Diante da grande competitividade do mercado, o branding ganha cada vez mais espaço e demostra ser uma ferramenta de suma importância para o alcance do diferencial competitivo. De acordo com um ranking dos países mais competitivos, elaborado pelo Foro Econômico Mundial, um grupo de economistas na Nova Zelândia identificou cinco indicadores relevantes para o design, no qual a difusão e aplicação da práxis do branding é apontado (BONSIEPE, 2011).

\subsection{GESTÃO DE MARCAS VERDES E O SETOR} HOTELEIRO

De acordo com a teoria de construção de marcas, defendida por Seireeni (2009) uma marca é resultado dos seguintes componentes: definição, propósito, vantagens, audiência e personalidade. Esses componentes coletivamente sugerem o posicionamento da marca. O posicionamento da marca é portanto, é a promessa inerente à marca que certas coisas serão entregues conforme esperado (SEIREENI, 2009, p. 17) .

A gestão de marcas verdes trabalha o posicionamento da marca de forma a direcioná-la à corrente da sustentabilidade. O termo em inglês, green branding, segundo Braun (2008) foi identificado em estudos conduzidos por Hartmann et al. (2004, 2005 e 2006) relacionados ao consumo de marcas posicionadas por seus atributos ecológicos. De acordo com Hartmann e Ibánez (2006) as marcas verdes podem evocar emoções positivas em determinados grupos-alvo simplesmente por oferecer informações sobre os atributos do produto ambientalmente saudáveis.

A temática verde, portanto, refere-se aos atributos agregados a uma marca relacionados à redução do seu impacto ambiental e a sua percepção como ambientalmente comprometida e confiável, de forma a gerar valor para a empresa. Sharp (2013) salienta que as organizações que se empenham a construir marcas verdes, muitas vezes não sinalizam adequadamente esse processo para os consumidores, apesar desta ser uma questão importante, dada a proliferação de marcas verdes nos últimos anos em quase todas as categorias de bens de consumo. "Essas marcas verdes cobrem uma gama de reivindicações de sustentabilidade começando com preocupações ambientais, tais como o material e consumo de energia, mas agora abrangem questões como a obtenção sustentável de produção material e orgânica, ou preocupações sociais mais amplas, tais como comércio justo e testes sem animais (SHARP, 2013, p. 110).

O green branding atua, portanto, de forma a possibilitar que as organizações possam gerir suas marcas focadas em projetos eco-sustentáveis, que abranjam o desenvolvimento do produto e os possíveis serviços que possam ser oferecidos aos consumidores, visando a diminuição dos impactos sociais e ambientais, e aumentando a satisfação do usuário. Segundo Lane (2010) as organizações estão despertando para a importância da gestão de marcas verdes, onde a divulgação de produtos e serviços ecológicos e práticas de negócios sustentáveis será difundida e rentável.

Trazendo tal reflexão para o segmento hoteleiro, percebe-se que a prerrogativa social e ambiental nas práticas gerenciais também atingiu o setor de hospedagem, que assim como outras empresas e organizações, tem adotado o uso de relatórios TBL ou GRI (Global Initiative Reporting) como forma de comprovar perante as partes interessadas a sua preocupação com as questões sociais e ambientais, além das econômicas (BARROS, 2013).

Com perfis de clientes culturalmente e financeiramente diversificados, e tendo como objetivo, segundo Cavassa (2001) atingir um 
mercado potencial afim de manter a taxa máxima de ocupação do estabelecimento, a qualidade do serviço, a rentabilidade, a competitividade e a imagem - que assegura o prestígio do hotel com base nos serviços prestados, é inevitável que o setor de hospedagem implemente práticas de sustentabilidade nos seus negócios.

Além da preocupação em atender as exigências por parte dos clientes, essas práticas de sustentabilidade no setor hoteleiro são encontradas em legislações e regulamentações. De acordo com Topke et al. (2011), existe um convênio entre o Instituto Brasileiro de Turismo (Embratur) e a Associação Brasileira da Indústria de Hotéis (ABIH), que apresenta um sistema de classificação hoteleira, o qual introduz o conceito de responsabilidade e gestão ambiental como critério classificatório.

Além do convênio, a Lei No 11.771, de 17 de Setembro de 2008 dispõe sobre a Política Nacional de Turismo, e destaca em seu artigo $6^{\circ}$, incisos VI e VII que possui o intuito de promover, entre outros objetivos, a proteção do meio ambiente, da biodiversidade e do patrimônio cultural de interesse turístico e a atenuação de passivos socioambientais eventualmente provocados pela atividade turística.

O Sistema Brasileiro de Classificação de Meios de Hospedagem (SBClass), instituído pela Portaria no 100, de 16 de Junho 2011 do Ministério do Turismo, estabelece critérios de classificação, cria o Conselho Técnico Nacional de Classificação de Meios de Hospedagem (CTClass), e determina no Artigo 9o, três aspectos importantes para classificar em categorias os hotéis: I - serviços prestados; II - qualidade da infraestrutura de instalações e equipamentos; III - variáveis e fatores relacionados com o desenvolvimento sustentável, tais como conceitos ambientais, relações com a sociedade, satisfação do usuário.

Neste contexto, observa-se a importância da integração da sustentabilidade nas operações hoteleiras, reforçando assim a necessidade dos esforços na área de gestão de marcas verdes. A adoção dessa postura socioambiental responsável contribui para que o setor ho- teleiro ganhe visibilidade, seduza o público e consolide valores de credibilidade e legitimidade, por meio de marcas sustentavelmente corretas. Assim, fica evidente que a preocupação em assumir comportamentos socioambientais, além de ser uma prerrogativa de diferencial competitivo, é também uma exigência legal das organizações, especialmente das que atuam no setor de hospedagem.

\section{METODOLOGIA}

Para a realização do estudo, inicialmente foi realizada uma pesquisa bibliográfica, que segundo Gil (2002) ocorre com base em materiais já elaborados e permite ao investigador compreender uma gama de fenômenos mais ampla do que aquela que poderia pesquisar diretamente.

Para o estudo de campo, que previa a análise da gestão da sustentabilidade e da gestão de marcas verdes, da rede hoteleira de Brasília, optou-se pelo uso do questionário autoaplicado, baseado nos estudos realizados por Peres Júnior e Rezende (2011), Viegas (2008) e Polonsky e Rosenberger (2011), como instrumento de coleta de dados.

$\mathrm{O}$ instrumento adotado foi construído com escala tipo Likert de cinco pontos, e abordava uma série de questões referentes às práticas sustentáveis relacionadas ao setor hoteleiro, as quais foram divididas de acordo com as dimensões ambiental, sociocultural e econômica, assim como questões acerca da gestão de marcas e gestão de marcas verdes.

A coleta dos dados foi realizada entre os meses de setembro de 2013 e abril de 2014 e a maior parte executada por meio do processo de preenchimento dos questionários pelos gerentes, na presença do pesquisador. No total dos 42 hotéis que integram o Setor Hoteleiro Norte e Sul de Brasília, foram obtidas 33 respostas, correspondendo a um percentual de $78,5 \%$ do total de amostras, todas com enquadramento do empreendimento na categoria - Hotel. 


\subsection{TRATAMENTO DOS DADOS - ANÁLISE ESTATÍSTICA}

Os dados obtidos na coleta de dados foram analisados mediante ferramenta de análise estatística descritiva com o intuito de verificar o nível de adoção de práticas ambientais no setor hoteleiro de Brasília. A partir da análise do conteúdo das afirmações para as variáveis escalares, (afirmações medidas em escala de concordância do tipo Lickert de cinco pontos), foram definidas três dimensões relacionadas às práticas de gestão da sustentabilidade: Responsabilidade Sociocultural, Responsabilidade Ambiental, Responsabilidade Econômica, além da dimensão Gestão de Marcas. Para cada dimensão foram analisadas as medidas de posição: média (média aritmética) e mediana (valor que divide a amostra na metade), além da análise de correlação (indicados os coeficientes de correlação de Pearson entre as dimensões do estudo).

Essas técnicas foram realizadas no softwa- re estatístico SPSS, baseadas na literatura especializada da área (COSTA, 2011; HAIR et al. 2005; LATTIN et al. 2011).

\section{APRESENTAÇÃO E ANÁLISE DOS DADOS}

Considerando os dados coletados por meio do questionário autoaplicado, pode-se observar nas tabelas a seguir o detalhamento das três dimensões relacionadas às práticas da gestão da sustentabilidade - responsabilidade Sociocultural, responsabilidade Ambiental e responsabilidade Econômica, e posteriormente o detalhamento acerca da dimensão relacionada a gestão de marcas. As tabelas a seguir demonstram os achados da coleta de dados, apresentando as medidas de posição: média (média aritmética) e mediana (valor que divide a amostra na metade) e as análises são realizadas com base nas amostras estudadas.

Tabela 1: Medidas descritivas - responsabilidades socioculturais

RESPONSABILIDADES SOCIOCULTURAIS

\begin{tabular}{|l|c|c|}
\hline \multicolumn{1}{|c|}{ VARIÁVEL } & MÉDIA & MEDIANA \\
\hline $\begin{array}{l}\text { 1. O empreendimento adota medidas de incentivo de manutenção de recursos } \\
\text { humanos, com vista à redução da rotatividade da mão de obra. }\end{array}$ & 4,06 & 4,00 \\
\hline $\begin{array}{l}\text { 2. O empreendimento desenvolve projetos de auxílio às comunidades } \\
\text { mais carentes, dando bolsas de estudo, oferecendo cursos de capacitação } \\
\text { profissional, entre outros. }\end{array}$ & 2,83 & 3,00 \\
\hline $\begin{array}{l}\text { 3. O empreendimento é engajado em ações ou iniciativas voluntárias } \\
\text { promovidas por organizações comunitárias, governamentais ou não } \\
\text { governamentais, que tenham o objetivo de contribuir com o desenvolvimento } \\
\text { das comunidades locais. }\end{array}$ & 2,97 & 3,00 \\
\hline $\begin{array}{l}\text { 4. O empreendimento assegura que os salários pagos atendam no mínimo aos } \\
\text { pisos da categoria, usando referências sindicais regionais. }\end{array}$ & 4,68 & 5,00 \\
\hline $\begin{array}{l}\text { 5. O empreendimento assegura instalações destinadas aos trabalhadores que } \\
\text { atendam às condições mínimas de higiene, segurança e conforto. }\end{array}$ & 4,51 & 5,00 \\
\hline $\begin{array}{l}\text { 6. O empreendimento promove a divulgação da cultura local entre os seus } \\
\text { clientes. }\end{array}$ & 3,66 & 4,00 \\
\hline $\begin{array}{l}\text { 7. O empreendimento implementa programas de saúde para seus } \\
\text { trabalhadores, extensivos às suas famílias }\end{array}$ & 3,71 & 4,00 \\
\hline 8. O empreendimento estabelece áreas devidamente sinalizadas para fumantes. & 4,08 & 3,81 \\
\hline MEDIDA GERAL & & 3,87 \\
\hline
\end{tabular}

Fonte: Dados da pesquisa (2014) 
Percebe-se, nas estatísticas descritivas da dimensão de Responsabilidades socioculturais, que as variáveis com maiores médias e medianas (ou seja, com os mais altos graus de concor-

Tabela 2: Medidas descritivas - responsabilidade ambiental

\begin{tabular}{|c|c|c|}
\hline \multicolumn{3}{|l|}{ RESPONSABILIDADE AMBIENTAL } \\
\hline VARIÁVEL & MÉDIA & MEDIANA \\
\hline $\begin{array}{l}\text { 1. O planejamento e operação do paisagismo do empreendimento foi } \\
\text { efetuado, minimizando os impactos ambientais, refletindo o ambiente natural } \\
\text { do entorno, inclusive com o uso de espécies nativas (desde que não sejam } \\
\text { provenientes de extração ilegal) }\end{array}$ & 3,57 & 4,00 \\
\hline $\begin{array}{l}\text { 2. O empreendimento estabelece e mantem procedimentos para identificar } \\
\text { o potencial de risco, prevenir a ocorrência e atender a acidentes e situações } \\
\text { de emergência na área do empreendimento ou por ele causados, bem como } \\
\text { mitigar os impactos ambientais deles }\end{array}$ & 3,94 & 4,00 \\
\hline $\begin{array}{l}\text { 3. Conserva área natural própria empregando as boas práticas de proteção e } \\
\text { manejo conforme o previsto na legislação }\end{array}$ & 4,06 & 4,00 \\
\hline $\begin{array}{l}\text { 4. Prioriza o uso de materiais de construção disponíveis na região e originados } \\
\text { de fontes sustentáveis }\end{array}$ & 3,83 & 4,00 \\
\hline $\begin{array}{l}\text { 5. Assegura uma destinação final adequada para os resíduos não aproveitados } \\
\text { na construção e reforma }\end{array}$ & 4,11 & 4,00 \\
\hline $\begin{array}{l}\text { 6. O empreendimento planeja e implementa medidas para reduzir, reutilizar ou } \\
\text { reciclar os resíduos sólidos }\end{array}$ & 3,57 & 4,00 \\
\hline 7. O empreendimento realiza coleta seletiva dos resíduos sólidos & 3,74 & 4,00 \\
\hline 8. O empreendimento realiza a reciclagem dos resíduos orgânicos & 2,51 & 2,00 \\
\hline $\begin{array}{l}\text { 9. O empreendimento realiza o tratamento das águas residuárias (seja mediante } \\
\text { a conexão ao sistema público de coleta e tratamento, se ele existir, seja } \\
\text { mediante a existência de instalações de tratamento próprias) }\end{array}$ & 3,34 & 3,00 \\
\hline $\begin{array}{l}\text { 10. O empreendimento promove, quando aplicável, o reuso de águas } \\
\text { residuárias tratadas para atividades como rega, lavagem de veículos e outras } \\
\text { aplicações }\end{array}$ & 2,51 & 2,00 \\
\hline $\begin{array}{l}\text { 11. Os sabonetes e cosméticos para uso dos clientes e trabalhadores são } \\
\text { biodegradáveis }\end{array}$ & 3,40 & 4,00 \\
\hline $\begin{array}{l}\text { 12. O uso de substâncias nocivas, incluindo pesticidas, tintas, desinfetantes } \\
\text { e materiais de limpeza, é minimizado, e substituído quando disponíveis, por } \\
\text { produtos ou processos inócuos }\end{array}$ & 3,42 & 4,00 \\
\hline $\begin{array}{l}\text { 13. O armazenamento, uso, manuseio e descarte de produtos químicos são } \\
\text { devidamente geridos pelo empreendimento }\end{array}$ & 4,06 & 4,00 \\
\hline $\begin{array}{l}\text { 14. O empreendimento utiliza produtos de limpeza biodegradáveis, } \\
\text { caracteristicamente neutros e formulados a partir de matérias primas não } \\
\text { corrosivas e não tóxicas }\end{array}$ & 3,51 & 4,00 \\
\hline $\begin{array}{l}\text { 15. O empreendimento planeja e implementa medidas para minimizar a } \\
\text { emissão de ruídos das instalações, maquinaria e equipamentos, das atividades } \\
\text { de lazer e entretenimento, de modo a não perturbarem o ambiente natural, o } \\
\text { conforto dos hóspedes e das comunidades... }\end{array}$ & 4,06 & 4,00 \\
\hline $\begin{array}{l}\text { 16. O empreendimento planeja e implementa medidas para minimizar a } \\
\text { emissão de gases, odores e material particulado provenientes de veículos, } \\
\text { instalações e equipamentos }\end{array}$ & 3,71 & 4,00 \\
\hline $\begin{array}{l}\text { 17. O empreendimento planeja e implementa medidas para minimizar o } \\
\text { consumo de energia, como por exemplo utilizando técnicas para maximizar } \\
\text { a eficiência energética, tais como, isolamento térmico de paredes e forros, } \\
\text { ventilação natural. }\end{array}$ & 3,83 & 4,00 \\
\hline
\end{tabular}




\begin{tabular}{|l|c|c|}
\hline $\begin{array}{l}\text { 18. O empreendimento informa aos clientes o seu comprometimento com a } \\
\text { economia da energia e água e encoraja o seu envolvimento em programas } \\
\text { específicos como trocas não diárias de roupa de cama e toalhas }\end{array}$ & 3,88 & 4,00 \\
\hline $\begin{array}{l}\text { 19. O empreendimento planeja e implementa medidas para minimizar o } \\
\text { consumo de água, como a utilização de dispositivos para economia de água } \\
\text { (como, por exemplo, torneiras e válvulas redutoras de consume em banheiros, } \\
\text { lavabos, chuveiros e descargas) }\end{array}$ & 3,80 & 4,00 \\
\hline $\begin{array}{l}\text { 20. O empreendimento tem programas de inspeção periódica nas canalizações, } \\
\text { e sua manutenção, com vistas à minimização de perdas de água }\end{array}$ & 4,20 & 4,00 \\
\hline MEDIDA GERAL & 3,65 & 3,70 \\
\hline
\end{tabular}

dância) foram as com as seguinte afirmações: '4. O empreendimento assegura que os salários pagos atendam no mínimo aos pisos da categoria, usando referências sindicais regionais' com média de 4,68 e mediana de 5; e '5. O empreendimento assegura instalações destinadas aos trabalhadores que atendam às condições mínimas de higiene, segurança e conforto', com média de 4,51 e mediana de 5,00. A variável que apresentou em média os menores graus de concordância foi a '2. O empreendimento desenvolve projetos de auxílio às comunidades mais carentes, dando bolsas de estudo, oferecendo cursos de capacitação profissional, entre outros', com média de 2,97 e mediana de 3,00.

Analisando mais detalhadamente o conteúdo das variáveis, é possível perceber que há uma tendência das médias serem maiores em termos da responsabilidade social interna (mais voltada para os colaboradores), do que em relação às variáveis que classificadas como de responsabilidade social externa (relações com a comunidade e clientes).

Nas medidas da dimensão de Responsabilidade Ambiental, tem-se uma média geral de 3,65 e uma mediana de 3,70. Analisando cada variável, é possível perceber que a afirmação com maior índice de concordância foi '20. O empreendimento tem programas de inspeção periódica nas canalizações, e sua manutenção, com vistas à minimização de perdas de água' com média de 4,20 e mediana de 4,00. As afirmações com menores médias foram ' 8 . 0 empreendimento realiza a reciclagem dos resíduos orgânicos' e '10. O empreendimento promove, quando aplicável, o reuso de águas residuárias tratadas para atividades como rega, lavagem de veículos e outras aplicações', ambas com 2,51 de média e e 2,00 de mediana. Estes dados demonstram que o setor hoteleiro tem uma maior preocupação com as perdas de água em relação à reciclagem de resíduos e reuso de água. Este fato justifica-se pela variável "perdas de água" representar um maior custo para os empreendimentos enquanto que as variáveis "reciclagem de resíduos orgânicos" e "reuso de águas residuárias" não representam, para o empreendimento, significativa vantagem econômica. $\mathrm{Na}$ dimensão Econômica, percebe-se médias mais

Tabela 3: Medidas descritivas - responsabilidade econômica

\begin{tabular}{|c|c|}
\hline \multicolumn{2}{|c|}{ RESPONSABILIDADE ECONÔMICA } \\
\hline VARIÁVEL & \\
\hline $\begin{array}{l}\text { 1. O empreendimento planeja e } \\
\text { implementa produtos e serviços } \\
\text { considerando as expectativas dos clientes }\end{array}$ & 4,00 \\
\hline $\begin{array}{l}\text { 2. Todos os funcionários recebem } \\
\text { orientação e treinamento periódico sobre } \\
\text { as suas funções e responsabilidades em } \\
\text { relação ao meio ambiente, social, cultural, } \\
\text { econômica, qualidade, questões de saúde e } \\
\text { segurança }\end{array}$ & 4,00 \\
\hline $\begin{array}{l}\text { 3. Possui monitoramento das expectativas } \\
\text { e impressões do hóspede em relação } \\
\text { aos serviços ofertados, incluindo meios } \\
\text { para pesquisar opiniões, reclamações e } \\
\text { solucioná-las. }\end{array}$ & 4,00 \\
\hline
\end{tabular}


altas do que nas dimensões anteriores, com um média geral de 4,08 e mediana de 4,00. A variável com maior média foi ' 3 . Possui monitoramento das expectativas e impressões do hóspede em relação aos serviços ofertados, incluindo meios para pesquisar opiniões, reclamações e solucioná-las', com média de 4,40 e mediana 4,00. Já a variável com a menor média foi ' 2 . Todos os funcionários recebem orientação e treinamento periódico sobre as suas funções e responsabilidades em relação ao meio ambiente, social, cultural, econômica, qualidade, questões de saúde e segurança', com média 3,63 e mediana 4,00. Estes dados demonstram que o empreendimento tem uma maior preocupação com o monitoramento das expectativas e impressões dos hóspedes em relação aos serviços ofertados do que com a orientação e treinamento dos funcionários com relação às práticas sustentáveis que poderiam ser adotadas. Por meio destes dados pode-se observar que, para o empreendimento, a adoção de práticas sustentáveis não é um fator decisivo na escolha do hotel pelo hóspede, não justificando, dessa forma, a sua adoção pelos gestores.

As questões elaboradas para avaliar as práticas relacionadas à Gestão de Marcas, em sua maioria também foram constituídas com

Tabela 4: Medidas descritivas - Gestão de marcas

\begin{tabular}{|c|c|c|}
\hline \multicolumn{3}{|l|}{ GESTÃO DE MARCAS } \\
\hline VARIÁVEL & MÉDIA & MEDIANA \\
\hline 1. O empreendimento avalia a(s) sua(s) marca(s). & 4,31 & 5,00 \\
\hline 2. A avaliação da(s) marca(s) melhora a comunicação com os acionistas da empresa. & 4,40 & 5,00 \\
\hline $\begin{array}{l}\text { 3. Os funcionários são encorajados a capitalizar no seu papel de embaixadores do processo } \\
\text { de construção de marca. }\end{array}$ & 4,17 & 5,00 \\
\hline $\begin{array}{l}\text { 4. O empreendimento utiliza a estratégia da temática verde para incrementar o valor da } \\
\text { imagem de marca e gerar valor para a empresa (conceito green brand). }\end{array}$ & 3,26 & 3,00 \\
\hline $\begin{array}{l}\text { 5. O empreendimento utiliza um conjunto específico de atributos e benefícios de } \\
\text { marca relacionados à redução do impacto ambiental da marca e sua percepção como } \\
\text { ambientalmente favorável. }\end{array}$ & 3,37 & 3,00 \\
\hline $\begin{array}{l}\text { 6. O empreendimento realiza esforços para ser reconhecido como uma operação } \\
\text { ambientalmente consciente que promove e pratica eficiência energética, conservação } \\
\text { e reciclagem, enquanto ao mesmo tempo fornece aos hóspedes do hotel um produto } \\
\text { sustentável. }\end{array}$ & 3,60 & 5,00 \\
\hline $\begin{array}{l}\text { 7. Os funcionários são treinados para praticar as medidas sustentáveis - desde o gerente até } \\
\text { as camareiras, além de terem a função de explicar aos hóspedes por que o hotel adotou tais } \\
\text { normas. }\end{array}$ & 3,68 & 5,00 \\
\hline $\begin{array}{l}\text { 8. O empreendimento acredita que seus ativos humanos, tais como talento, habilidade e } \\
\text { capacitação de funcionários são elementos contributivos para a valorização da sua marca. }\end{array}$ & 4,66 & 5,00 \\
\hline $\begin{array}{l}\text { 9. O empreendimento possui um sistema de medição e monitoramento da satisfação do } \\
\text { cliente, que consiste na identificação das expectativas, medição da satisfação, elaboração de } \\
\text { estratégias de melhoria da qualidade e implantação das melhorias. }\end{array}$ & 4,60 & 5,00 \\
\hline $\begin{array}{l}\text { 10. O empreendimento considera a sustentabilidade um aspecto estratégico e lucrativo dos } \\
\text { negócios e um recurso para o fortalecimento da marca. }\end{array}$ & 4,08 & 5,00 \\
\hline MEDIDA GERAL & 4,01 & 4,20 \\
\hline
\end{tabular}


afirmações medidas em escala de concordância do tipo Lickert, de 5 pontos. As tabelas a seguir demonstram a análise estatística desses dados, apresentando as medidas de posição: média (média aritmética) e mediana (valor que divide a amostra na metade) e as análises são realizadas com base nas amostras estudadas.

De forma geral, percebe-se que a dimensão Gestão de Marcas possui uma média geral de 4,01 e mediana de 4,20. Especificamente a variável '8. O empreendimento acredita que seus ativos humanos, tais como talento, habilidade e capacitação de funcionários são elementos contributivos para a valorização da sua marca' obteve a maior média $(4,66)$ e uma mediana de 5,00 . Por outro lado, a variável '4. $\mathrm{O}$ empreendi-

\begin{tabular}{|l|l|l|l|l|}
\hline & $\begin{array}{l}\text { RESPONSABILIDADE } \\
\text { SOCIOCULTURAL }\end{array}$ & $\begin{array}{l}\text { RESPONSABILIDADE } \\
\text { AMBIENTAL }\end{array}$ & $\begin{array}{l}\text { RESPONSABILIDADE } \\
\text { ECONÔMICA }\end{array}$ & $\begin{array}{l}\text { GESTÃO DE } \\
\text { MARCAS }\end{array}$ \\
\hline $\begin{array}{l}\text { RESPONSABILIDADE } \\
\text { SOCIOCULTURAL }\end{array}$ & 1 & & & \\
\hline $\begin{array}{l}\text { RESPONSABILIDADE } \\
\text { AMBIENTAL }\end{array}$ & $0,725^{* *}$ & 1 & 1 & \\
\hline $\begin{array}{l}\text { RESPONSABILIDADE } \\
\text { ECONÔMICA }\end{array}$ & $0,489^{* *}$ & $0,631^{* *}$ & $0,474^{* *}$ & 1 \\
\hline $\begin{array}{l}\text { GESTÃO DE } \\
\text { MARCAS }\end{array}$ & $0,464^{* *}$ & $0,687^{* *}$ & & Fonte: Dados da Pesquisa \\
\hline
\end{tabular}

Tabela 5: Medidas descritivas - todas as dimensões

\begin{tabular}{|c|c|c|}
\hline \multicolumn{3}{|c|}{ TODAS AS DIMENSÕES } \\
\hline DIMENSÃO & MÉDIA & MEDIANA \\
\hline SOCIOCULTURAL & 3,81 & 3,87 \\
\hline AMBIENTAL & 3,65 & 3,70 \\
\hline ECONÔMICA & 4,08 & 4,00 \\
\hline GESTÃO DE MARCAS & 4,01 & 4,20 \\
\hline
\end{tabular}

Fonte: Dados da pesquisa (2014)

a estratégia da temática verde para incrementar o valor da imagem de marca e gerar valor para a empresa (conceito green brand)' obteve a menor média $(3,26)$, com mediana 3,00 . Esses resultados sinalizam que a gestão da marca do hotel está menos ligada a questões associadas a gestão ambiental, comparativamente a questões de outros fatores.
Fonte: Dados da Pesquisa (2014)

Observando a tabela acima, que demonstra as medidas descritivas de todas as dimensões analisadas, tem-se a dimensão 'Econômica' com a maior média $(4,08)$ e mediana 4,00, e a dimensão 'responsabilidade ambiental' com menor média $(3,65)$ e mediana de 3,70. Esses resultados apresentam uma maior preocupação com os itens da dimensão econômica e de gestão de marcas, comparativamente aos itens de responsabilidade sociocultural e ambiental.

Considerando que a análise de correla-

Tabela 6: Análise de correlação

ção indica a força e a direção do relacionamento linear entre duas variáveis aleatórias, pode-se observar na tabela acima os coeficientes de correlação de Pearson entre as dimensões do estudo.

Percebe-se, portanto, que todas as dimensões estão correlacionadas entre si, a um grau de significância de $1 \%$. As dimensões responsabilidade Sociocultural e responsabilidade Ambiental possuem alto grau de correlação positiva comparativamente às demais, o que significa que quanto maior o grau de uma, maior será o grau da outra.

\section{CONSIDERAÇÕES FINAIS}

O cenário socioambiental atual exige mudanças urgentes para um modelo de desenvolvimento sustentável. Dessa forma, acredita-se que a gestão de marcas verdes, é uma importante ferramenta para o incremento da imagem 
do setor hoteleiro, fortalecendo a imagem de marca, por meio de valores como a proteção ao meio ambiente e o desenvolvimento sustentável.

Na pesquisa de campo, que se propôs a conhecer as práticas relacionada à gestão da sustentabilidade e a gestão de marcas, concluiu-se que a rede hoteleira estudada tem preocupação com os aspectos voltados para a sustentabilidade, no entanto, em sua maioria, implementam em baixa escala estratégias que favoreçam uma real gestão com base na sustentabilidade. Os gestores dos hotéis compreendem a importância da implantação de práticas sustentáveis no empreendimento, porém acreditam que estas práticas não são um diferencial competitivo para a escolha do hotel pelo hóspede e adotam principalmente os princípios relacionados ao atendimento da legislação vigente.

Ainda com relação a pesquisa de campo, os dados acerca da gestão de marcas, o resultado mais relevante, se refere ao fato da gestão de marca dos hotéis estar menos ligada a questões associadas a gestão ambiental, comparativamente a outros fatores. Essa informação é relevante e serve como um alerta a esse setor no que se refere ao seu desenvolvimento sustentável e vai de encontro com achados da revisão bibliográfica, que afirmam que para o turista do século XXI, importa muito a qualidade e a variedade de opções de lazer e hospedagem (Brasil, [2010]).

Caberia portanto, à união dos esforços entre gestão pública, iniciativa privada e comunidade local, para zelar que o desenvolvimento das operações hoteleiras ocorram de forma sustentável, garantindo medidas alternativas e lucrativas que considerem uma gestão de marca imbuída de valores éticos e sustentáveis.

\section{REFERÊNCIAS}

ALBERTON, A.; COSTA JR., N.C.A. Meio Ambiente e Desempenho Econômico-Financeiro: Benefícios dos Sistemas de Gestão Ambiental (SGAs) e o Impacto da ISO 14001 nas Empresas Brasilei- ras. RAC-Eletrônica, v. 1, n. 2, art. 10, p. 153-171, Maio/Ago. 2007.

ALVES, Ricardo R.; JACOVINE, Laércio A. G. Marketing verde: estratégias para o desenvolvimento da qualidade ambiental nos produtos. Jundiaí: Paco Editorial, 2014.

BARROS, Flávio Eurico F. de. Sustentabilidade no Setor Hoteleiro. In: Gestão para o desenvolvimento sustentável: desafios e proposições para a sustentabilidade socioambiental. São Paulo: Editora Globus, 2013. P. 165-179

BRASIL. Ministério do turismo. Proposta estratégica de organização turística Copa do Mundo 2014 Brasil. Brasília, DF. [2010] Disponível em: <http://www.dadosefatos.turismo.gov.br/ export/sites/default/dadosefatos/outros_estudos/downloads_outrosestudos/BRASIL_final_ NOVO.pdf>. Acesso em: 10 ago. 2014.

BRAUN, Jan Raphael R. Green Branding: design gráfico e gestão de marcas de Ongs ambientalistas. Programa de Pós-Graduação em Design e Expressão Gráfica. Universidade Federal de Santa Catarina, 2008.

BONSIEPE, Gui. Design, Cultura e Sociedade. São Paulo: Blucher, 2011.

BÜRDEK, Bernhard E. História, teoria e prática do design de produtos. São Paulo: Edgard Blücher, 2006.

CAVASSA, César R. Hotéis: gerenciamento, segurança e manutenção. São Paulo: Roca, 2001.

COSTA, F. J. Mensuração e desenvolvimento de escalas: aplicações em Administração. Rio de Janeiro, 2011.

ELWOOD, lain. O Livro essencial das marcas: tudo o que você precisa saber, em mais de 100 técnicas para aumentar o valor das marcas. São Paulo: Clio Editora, 2004.

GIL, Antonio Carlos. Como elaborar projetos de 
pesquisa. 2. ed. São Paulo: Atlas, 2002.

HAIR Jr.; ANDERSON, R. E.; TATHAM, R. L.; BLACK, W. C. Análise multivariada de dados. 5 ed. Porto Alegre: Bookman, 2005.

HARTMANN, Patrick; IBÁNEZ, VANESSA A. Effects of green brand communication on brand associations and attitude. International Advertising and Communication. Germany: Gabler Edition Wissenschaft, 2006.

HARTMANN, P., SAINZ, F. J. F. \& IBÁÑEZ, V. A.. Superando los límites medioambientales de la empresa: Un studio experimental del efecto del posicionamiento ecológico en la actitud hacia la marca. Cuadernos de Gestión, v. 4, no1, p. 8395, 2004.

HARTMANN, P, IBÁÑEZ, V. A. \& SAINZ, F. J. F.. Green branding effects on attitude: functional versus emotional positioning strategies. Markenting Intelligence \& Planning, v.23, no1, p. 9-29, 2005.

HEALEY, Matthew. What is branding? Switzerland: RotoVision, 2008.

LANE, Eric. L. Consumer Protection in the Eco-mark Era: Prelimitary Survey and Assessment of Anti-grenwashing Activity and Eco-mark Enforcement. The John Marshall Review of Intellectual Property Law. New Orleans, 2010.

LATTIN, J; CARROL, J. D.; GREEN, P. E. Análise de dados multivariados. São Paulo: Cengage Learning, 2011.

MANZINI, E.; VEZZOLI, C. O desenvolvimento de produtos sustentáveis: os requisitos ambientais dos produtos industriais. São Paulo: Editora da Universidade de São Paulo, 2002.

MOZOTA, B. Gestão do design: usando o design para construir valor de marca e inovação corporativa. Porto Alegre: Bookman, 2011.

PEREZ, C. Signos da Marca: Expressividade e
Sensorialidade. São Paulo: Pioneira Thomson Learning, 2004.

PERES JÚNIOR, M. R.; REZENDE, D.C. Gestão da Sustentabilidade no segmento hoteleiro: estudo dos meios de hospedagem de Monte Verde, MG. Caderno Virtual de Turismo. Rio de Janeiro. v. 11, n 2, p. 234-252, ago.2011.

POLONSKY, M. J.; ROSENBERGER, P.J. Reevaluating green marketing: a strategic approach. Bus Horizons, v. 44, n. 5, p. 21-30, 2011.

SEIREENI, Richard. The Gort Cloud: The invisible Force Powering Today's Most Visible Green Brands. Vermont: Chelsea Green Publishing Company, 2009.

SHARP, Anne. Sustainable marketing in principle and practice. Sustainable Business - Theory and Practice of Business under Susteinability Principles. Geoffrey Welss, 2013.

TEIXEIRA, Joselena de A.; GONTIJO, Leila A.; MARTINS, Rosane F. Marketing e Design. IXXIV Encontro Nacional de Engenharia de Produção. Florianópolis, SC, 2004, Anais. 